\title{
LANGUAGE AND COGNITION IN VERY LOW BIRTH WEIGHT PRETERM INFANTS WITH PELCDO APPLICATION
}

\author{
Karina Elena Bernardis Bühler', Suelly Cecilia Olivan Limongi ${ }^{2}$, Edna Maria de Albuquerque Diniz ${ }^{3}$
}

\begin{abstract}
The performance of very low birth weight preterm infants, in terms of cognition and expressive language, was analyzed and compared with that of term infants with the Protocol for Expressive Language and Cognition Development Observation (PELCDO). The study involved 12 very low birth weight preterm infants and 20 term infants, all of whom were evaluated monthly. Sessions were videotaped, and data were analyzed according to this specific protocol. Our results suggest that cognition and expressive language develop significantly later in very low birth weight preterm infants than in the term. We found positive correlations for cognitive and expressive language development, the delay becoming more evident after 6 months of age, persisting through the sensorimotor period, and continuing into the beginning of preoperational period, indicating the importance of follow-up evaluation, defining the true needs of such infants and identifying the ideal moment for speech-language intervention.
\end{abstract}

KEY WORDS: infant very low birth weight, language, cognition, infant, premature, protocol.

\section{Linguagem e cognição em bebês pré-termo muito baixo peso por meio da aplicação do PODCLE}

\begin{abstract}
Resumo - O desempenho de bebês pré-termo muito baixo peso em relação ao desenvolvimento cognitivo e de linguagem expressiva foi analisado e comparado com o de bebês de termo com o Protocolo para Observação do Desenvolvimento Cognitivo e de Linguagem Expressiva (PODCLE). $O$ estudo envolveu 12 bebês prétermo muito baixo peso e 20 bebês de termo acompanhados mensalmente. Todas as sessões foram filmadas em videotape e os dados analisados segundo o protocolo específico. Nossos resultados mostraram que o desenvolvimento cognitivo e da linguagem expressiva ocorreu significativamente mais tarde nos bebês prétermo muito baixo peso. Nós encontramos correlações positivas entre o desenvolvimento cognitivo e de linguagem expressiva, o atraso foi mais evidente após os seis meses de idade mantendo-se durante todo 0 período sensório-motor e início do pré-operatório, indicando a importância do seguimento, definindo as necessidades reais destas crianças e indicando o melhor momento para intervenção fonoaudiológica.
\end{abstract}

PALAVRAS-CHAVE: recém-nascido de muito baixo peso, linguagem, cognição, prematuro, protocolos.

In children who had been very low birth weight (VLBW) preterm infants, speech and language disorders have been reported in terms of reception and expression ${ }^{1-3}$. In addition, it has been shown that such children are at risk for cognitive and behavioral problems, including lower IQ, learning disabilities, excessive distraction, hyperactivity, and working memory deficits ${ }^{4-9}$. Although such verbal problems are not evident during the first years of life, they can have a significant negative impact on the social and academic life of the child ${ }^{6}$.

The focus of the present study was cognitive and lan- guage development during the sensorimotor period and the beginning of the preoperational period. This is a crucial phase in the preparation and acquisition of the first words and syntactic construction, since sensorimotor intelligence allows the notions of subject, verb, predicate, and object permanence to be constructed ${ }^{10}$.

In this period the children typically use deictic and representative gestures and various authors have suggested that oral expression development is determined by the quantity and quality of gestures and signs a child uses during the early phase of language development ${ }^{11-14}$. In ear-

\footnotetext{
Hospital Universitário, University of São Paulo, São Paulo SP, Brazil: 'PhD, Speech and Language Therapist, Hospital Universitário, University of São Paulo; ${ }^{2}$ PhD Associate Professor, Department of Speech, Language and Hearing Sciences, School of Medicine, University of São Paulo; ${ }^{3}$ PhD Associate Professor, Department of Pediatrics, School of Medicine, University of São Paulo, Coordinator of Researches in Neonatology, Hospital Universistário, University of São Paulo. Financing: FAPESP process n 06/55866-9.
}

Received 15 September 2008, received in final form 11 December 2008. Accepted 4 March 2009.

Dra. Karina Elena Bernardis Bühler - Rua Aliança Liberal 1015 / 101 - 05088-000 São Paulo SP. Brasil. E-mail: kbuhler@hu.usp.br 
ly language development, a child uses gestures as substitutes for, or in conjunction with, the linguistic signals in order to facilitate communication. Once a child has acquired a broader linguistic repertoire (through social relationships, as well as through interaction with objects and situations), the use of gestures decreases ${ }^{15-17}$.

In the genetic epistemology model, observing the behavior of the child is crucial, and the observer plays an important role, determining how the knowledge is built. It is a descriptive model with qualitative value, but it needs an objective observation ${ }^{18}$.

Therefore, the use of protocols based on these theoretical principles is appropriate. The protocol for expressive language and cognition development observation (PELCDO) is one such protocol ${ }^{19,20}$, which is applied to the sensorimotor period and the beginning of the preoperational period.

The aim of the present study was to place and describe the performance of VLBW preterm infants, in terms of cognition and expressive language during the sensorimotor and the beginning of the preoperational period, and to compare it with that of term infants with PELCDO application.

\section{METHOD}

This study was approved by the Ethics Committee of the University of São Paulo University Hospital (process n? 592/05), as well as by the Ethics Committee for the Analysis of Research Projects of the University of São Paulo School of Medicine Hospital das Clínicas, (process no. 082/07). Written informed consent was obtained from the parents or legal guardians of all study participants.

The study was carried out over a period of two years and three months. The study sample was composed of 12 of VLBW preterm infants (VLBW-PI group), the mean gestational age was 29.4 weeks, and the mean birth weight was $1073 \mathrm{~g}$, all infants were born at the University of São Paulo University Hospital between March of 2005 and February of 2006 and monitored at the University Hospital Outpatient Clinic for High-Risk Newborns; and a group of 20 term infants (TI group), monitored at the University Hospital Pediatric Outpatient Clinic, at the University Hospital Day Care Center, or both. The mean gestational age was 39.1 weeks, and the mean birth weight was $3291 \mathrm{~g}$.

The criteria for inclusion in the VLBW-PI group were being less than 34 weeks of gestational age (according to the date of last menstrual period) and having a birth weight equal to or lower than $1500 \mathrm{~g}$, as well as presenting no major malformations, genetic syndromes, severe neonatal asphyxia, hearing impairment and visual impairment. The following were the criteria for inclusion in the TI group: having presented no prenatal, perinatal, or postnatal complications; being of an appropriate gestational age; presenting a birth weight of between $2500 \mathrm{~g}$ and $3999 \mathrm{~g}$. All infants should have been exposed only to Brazilian Portuguese.

Tables 1 and 2 presents the distribution of the children according to delivery, gender, gestational age, birth weight and bulletin Apgar for VLBW-PI group and TI group respectively.

In conducting the present study, we used the following: the PELCDO ${ }^{19}$; a tape transcription protocol; a Sony $8 \mathrm{~mm}$ video recorder; and evaluation material according to the protocol.

From inclusion in the study until 18 months of age, infants in both groups underwent monthly, 30-min evaluations in which cognition and expressive language were observed and recorded according to the PELCDO. There were two observers (raters), both of whom were blinded to the group to which a given infant belonged. In accordance with the standards of the institutions at which the infants were evaluated, corrected ages were used for the infants in the VLBW-PI group.

All sessions were videotaped and transcribed. The data were analyzed according to the PELCDO. In terms of cognitive development, the following aspects were evaluated:

Table 1. Distribution and characterization of very low birth weight preterm infants group.

\begin{tabular}{|c|c|c|c|c|c|c|c|}
\hline № & Participant & Delivery & Gender & G.A. & Weight & Apgar 10 & Apgar 50 \\
\hline 1 & V.F. & V & $M$ & 29 & 1020 & 4 & 7 \\
\hline 2 & T.S. & V & $\mathrm{F}$ & $296 / 7$ & 910 & 4 & 8 \\
\hline 3 & R.U.S. & V & M & 25 & 685 & 4 & 6 \\
\hline 4 & G.H.B. & V & $M$ & 31 & 1460 & 9 & 9 \\
\hline 5 & R.R.O. & V & M & $24 \quad 2 / 7$ & 560 & 4 & 4 \\
\hline 6 & P.D.S.A. & V & M & $323 / 7$ & 1170 & 2 & 8 \\
\hline 7 & V.R.N. & V & $\mathrm{F}$ & 29 & 990 & 8 & 9 \\
\hline 8 & L.G.O.S & V & M & $266 / 7$ & 955 & 7 & 9 \\
\hline 9 & M.S.C. & V & $\mathrm{F}$ & $315 / 7$ & 1135 & 4 & 6 \\
\hline 10 & D.G.O. & V & $M$ & $331 / 7$ & 1285 & 7 & 8 \\
\hline 11 & F.R.S. & V & $M$ & 28 & 1225 & 9 & 9 \\
\hline 12 & I.S.J. & C & $\mathrm{F}$ & $331 / 7$ & 1480 & 5 & 8 \\
\hline
\end{tabular}

C: cesarean; V: vaginal; G.A.: gestational age. 
Table 2. Distribution and characterization of term infants group.

\begin{tabular}{|c|c|c|c|c|c|c|c|}
\hline No & Participant & Delivery & Gender & G.A. & Weight & Apgar 19 & Apgar 50 \\
\hline 1 & L.P. & V & $\mathrm{F}$ & 40 & 3005 & 10 & 10 \\
\hline 2 & E.R.S.I & C & $\mathrm{F}$ & $394 / 7$ & 3180 & 9 & 10 \\
\hline 3 & F.R.S. & C & $M$ & $393 / 7$ & 3640 & 9 & 10 \\
\hline 4 & P.N.S. & C & $M$ & 38 & 2805 & 8 & 9 \\
\hline 5 & P.G.C.G. & C & $M$ & $394 / 7$ & 3130 & 9 & 10 \\
\hline 6 & A.C.C. & C & $\mathrm{F}$ & $395 / 7$ & 3995 & 10 & 10 \\
\hline 7 & F.M.C.F. & V & $M$ & $392 / 7$ & 3340 & 9 & 10 \\
\hline 8 & C.P.A.S. & V & $\mathrm{F}$ & $391 / 7$ & 3050 & 9 & 10 \\
\hline 9 & L.I.G.S. & C & $F$ & $384 / 7$ & 3310 & 9 & 10 \\
\hline 10 & E.N.S. & C & $M$ & 40 & 3660 & 8 & 9 \\
\hline 11 & Y.M.B. & v & $M$ & $381 / 7$ & 2765 & 9 & 9 \\
\hline 12 & A.A.C. & C & $\mathrm{F}$ & $392 / 7$ & 3230 & 8 & 9 \\
\hline 13 & J.S.R. & V & $\mathrm{F}$ & $395 / 7$ & 3205 & 8 & 9 \\
\hline 14 & G.V. & C & $\mathrm{F}$ & $393 / 7$ & 3130 & 9 & 10 \\
\hline 15 & A.F.R. & v & $M$ & $373 / 7$ & 3550 & 8 & 9 \\
\hline 16 & A.C.M.C & C & $F$ & 38 & 2980 & 9 & 9 \\
\hline 17 & M.F.S.N. & C & $M$ & $393 / 7$ & 3560 & 9 & 10 \\
\hline 18 & I.L.C. & V & $\mathrm{F}$ & $392 / 7$ & 3205 & 9 & 10 \\
\hline 19 & F.P.V. & $C$ & $M$ & $392 / 7$ & 3805 & 9 & 10 \\
\hline 20 & V.A.C.P. & V & $M$ & $40 \quad 2 / 7$ & 3280 & 9 & 10 \\
\hline
\end{tabular}

C: cesarean; V: vaginal; G.A.: gestational age.

$1^{\text {st }}$ and $2^{\text {nd }}$ phases of sensory-motor period - Sensorimotor scheme application (application of isolated schemes); displacement of objects in space (follows incompletely, follows completely).

$3^{\text {rd }}$ phase of sensory-motor period - Sensorimotor scheme application (application of coordinated schemes); object permanence (looks for the object partially hidden), motor scheme imitation (isolated schemes visible in the body).

$4^{\text {th }}$ phase of sensory-motor period-Object permanence (looks for the object totally hidden but not considering its displacements), motor scheme imitation (schemes not visible in the body), using objects as tools (support and string conduct).

$5^{\text {th }}$ phase of sensory-motor period - Object permanence (looks for the object totally hidden, considering only the visible displacements), motor scheme imitation (imitation of coordinated schemes), using objects as tools (the stick conduct), performs experiences with new objects.

$6^{\text {th }}$ phase of sensory-motor period - Object permanence (looks for the object totally hidden considering the visible and invisible displacements), simple symbolic schemes (applied in the body or in figurative objects).

Beginning of preoperational period - simple symbolic schemes (applied in non-figurative objects), combined symbolic schemes (combines two actions, combines three or more non-ordered actions, combines three or more ordered actions).
In terms of the development of expressive language, the aspects evaluated were as follows:

Set of productions I- Imitation of deictic or representative gestures, accompanied or not by vocalizations

Set of productions II - Differed imitation of deictic or representative gestures, accompanied or not by vocalizations.

Set of productions III - Differed imitation of representative gestures accompanied by vocal onomatopoeia or syllables with meaning. Production of syllables with meaning, monosyllabic words and/or interjections accompanied or not by deictic or representative gestures.

Set of productions IV - Production of onomatopoeic words and words with more than one syllable, accompanied or not by deictic or representative gestures.

Set of productions $\mathbf{V}$ - Production of combination of two or more words, accompanied or not by deictic or representative gestures.

In order to assure the reproducibility of the analysis, the results were validated by determining inter-rater reliability. The inter-rater reliability was $92 \%$ for observer 1 and $94 \%$ for observer 2 .

Parametric tests (analysis of variance) and nonparametric tests (Mann-Whitney test, Kruskal-Wallis test, and Spearman's correlation) were used for the statistical analysis of data. The level of significance was set at $5 \%$. 
Table 3. Distribution of cognitive scores over the months evaluated.

\begin{tabular}{|c|c|c|c|c|c|c|c|c|c|c|}
\hline \multicolumn{2}{|c|}{ Cognition } & \multirow{2}{*}{$\frac{\text { Mean }}{0.8}$} & \multirow{2}{*}{$\frac{\text { Median }}{1}$} & \multirow{2}{*}{$\frac{S D}{0.7}$} & \multirow{2}{*}{$\begin{array}{c}\text { CV } \\
85.7 \%\end{array}$} & \multirow{2}{*}{$\begin{array}{c}\text { Q1 } \\
0\end{array}$} & \multirow{2}{*}{$\frac{\text { Q3 }}{1}$} & \multirow{2}{*}{$\frac{N}{9}$} & \multirow{2}{*}{$\frac{\mathrm{Cl}}{0.4}$} & \multirow{3}{*}{$\begin{array}{c}\mathrm{P} \\
.799\end{array}$} \\
\hline Month 1 & VLBW-PI & & & & & & & & & \\
\hline & $\mathrm{TI}$ & 1.0 & 1 & 1.4 & $141 \%$ & 0.5 & 1.5 & 2 & 2.0 & \\
\hline \multirow[t]{2}{*}{ Month 2} & VLBW-PI & 1.4 & 1 & 1.0 & $68.3 \%$ & 1 & 2 & 7 & 0.7 & \multirow{2}{*}{.519} \\
\hline & TI & 1.0 & 1 & 0.0 & $0.0 \%$ & 1 & 1 & 2 & - & \\
\hline \multirow[t]{2}{*}{ Month 3} & VLBW-PI & 2.3 & 2 & 1.0 & $44.3 \%$ & 2 & 2.75 & 6 & 0.8 & \multirow{2}{*}{.746} \\
\hline & TI & 2.1 & 2 & 0.4 & $16.6 \%$ & 2 & 2 & 8 & 0.2 & \\
\hline \multirow[t]{2}{*}{ Month 4} & VLBW-PI & 3.0 & 3 & 0.8 & $27.2 \%$ & 2.5 & 3.5 & 7 & 0.6 & \multirow{2}{*}{.114} \\
\hline & TI & 3.6 & 4 & 0.5 & $14.3 \%$ & 3 & 4 & 8 & 0.4 & \\
\hline \multirow[t]{2}{*}{ Month 5} & VLBW-PI & 3.8 & 4 & 0.7 & $17.6 \%$ & 3 & 4 & 9 & 0.4 & \multirow{2}{*}{.154} \\
\hline & $\mathrm{TI}$ & 4.3 & 4 & 0.8 & $18.4 \%$ & 4 & 4.5 & 11 & 0.5 & \\
\hline \multirow[t]{2}{*}{ Month 6} & VLBW-PI & 4.4 & 4 & 0.8 & $17.8 \%$ & 4 & 4.5 & 7 & 0.6 & \multirow{2}{*}{$.006^{*}$} \\
\hline & TI & 5.8 & 6 & 0.7 & $11.5 \%$ & 5 & 6 & 9 & 0.4 & \\
\hline \multirow[t]{2}{*}{ Month 7} & VLBW-PI & 5.2 & 5 & 0.4 & $7.9 \%$ & 5 & 5 & 6 & 0.3 & \multirow{2}{*}{$.005^{*}$} \\
\hline & TI & 6.4 & 7 & 1.9 & $29.2 \%$ & 6 & 7 & 17 & 0.9 & \\
\hline \multirow[t]{2}{*}{ Month 8} & VLBW-PI & 6.4 & 6.5 & 1.1 & $16.6 \%$ & 5.75 & 7 & 8 & 0.7 & \multirow{2}{*}{$.003 *$} \\
\hline & TI & 7.9 & 8 & 2.5 & $32.3 \%$ & 8 & 8.75 & 14 & 1.3 & \\
\hline \multirow[t]{2}{*}{ Month 9} & VLBW-PI & 7.7 & 7 & 1.6 & $20.1 \%$ & 7 & 8 & 11 & 0.9 & 004 * \\
\hline & TI & 10.1 & 10 & 2.3 & $22.5 \%$ & 8 & 10.8 & 14 & 1.2 & \\
\hline Month 10 & VLBW-PI & 7.8 & 8 & 0.8 & $9.6 \%$ & 7.25 & 8 & 6 & 0.6 & 001* \\
\hline & TI & 12.7 & 12 & 2.6 & $20.8 \%$ & 11 & 14.5 & 15 & 1.3 & .001 \\
\hline Month 11 & VLBW-PI & 11.7 & 11.5 & 2.2 & $18.5 \%$ & 10.3 & 12.8 & 6 & 1.7 & $011^{*}$ \\
\hline & TI & 15.6 & 16.5 & 2.6 & $16.7 \%$ & 14.5 & 17.3 & 12 & 1.5 & .011 \\
\hline Month 12 & VLBW-PI & 12.0 & 13 & 2.4 & $20.4 \%$ & 10 & 13 & 5 & 2.1 & $005 *$ \\
\hline & TI & 16.8 & 17 & 1.9 & $11.5 \%$ & 16 & 18 & 11 & 1.1 & \\
\hline Month 13 & VLBW-PI & 14.6 & 14 & 2.9 & $20.1 \%$ & 12 & 16.5 & 7 & 2.2 & $017 *$ \\
\hline & TI & 17.9 & 18 & 1.2 & $6.7 \%$ & 17 & 19 & 16 & 0.6 & (017 \\
\hline Month 14 & VLBW-PI & 16.1 & 16 & 2.5 & $15.4 \%$ & 15.5 & 17 & 7 & 1.8 & 025 * \\
\hline & $\mathrm{TI}$ & 18.5 & 18.5 & 1.2 & $6.7 \%$ & 18 & 19.3 & 12 & 0.7 & $.0 \angle \sigma$ \\
\hline Month 15 & VLBW-PI & 16.8 & 18 & 1.8 & $10.6 \%$ & 16 & 18 & 5 & 1.6 & 009* \\
\hline & TI & 19.3 & 19 & 1.3 & $6.5 \%$ & 18.3 & 20 & 10 & 0.8 & .007 \\
\hline Month 16 & VLBW-PI & 17.9 & 17.5 & 1.1 & $6.3 \%$ & 17 & 18.3 & 8 & 0.8 & $012 *$ \\
\hline & TI & 19.5 & 19.5 & 1.2 & $6.0 \%$ & 19 & 20 & 10 & 0.7 & \\
\hline Month 17 & VLBW-PI & 17.0 & 17 & 1.9 & $11.0 \%$ & 17 & 18 & 5 & 1.6 & $020 *$ \\
\hline & TI & 19.2 & 19 & 1.1 & $5.9 \%$ & 18.3 & 19.8 & 10 & 0.7 & \\
\hline Month 18 & VLBW-PI & 18.2 & 18 & 1.1 & $6.2 \%$ & 18 & 19 & 10 & 0.7 & $<001 *$ \\
\hline & $\mathrm{TI}$ & 20.5 & 20 & 1.1 & $5.5 \%$ & 20 & 21.5 & 15 & 0.6 & $<.001$ \\
\hline
\end{tabular}

SD: standard deviation; CV: coefficient of variance; Q1: first quartile; Q3: third quartile; Cl: confidence interval; VLBW-PI: very low birth weight preterm infants; TI: term infants. *Statistically significant.

\section{RESULTS}

Table 3 presents the results of the monthly cognitive development analyses for both groups. We found statistically significant differences between the two groups in all months from month 6 onward, cognitive development scores being higher in the TI group.

Table 4 presents the results of the monthly evaluations of expressive language development for both groups. We found statistically significant differences between the two groups in months $9,11,12,13,14,16$, and 18, expressive language development scores being higher in the TI group. In months 10, 15 and 17, that difference presented only a tendency toward statistical significance.

We found statistically significant positive correlations between cognition and expressive language in both groups (Table 5), cognitive score increasing in parallel with expressive language score, and vice-versa. The correlations between the two skills were calculated only from month 
Table 4. Distribution of expressive language scores over the months in which it was quantifiable.

\begin{tabular}{|c|c|c|c|c|c|c|c|c|c|c|}
\hline \multicolumn{2}{|c|}{ Expressive language } & \multirow{2}{*}{$\begin{array}{c}\text { Mean } \\
0.1\end{array}$} & \multirow{2}{*}{$\frac{\text { Median }}{0}$} & \multirow{2}{*}{$\frac{S D}{0.4}$} & \multirow{2}{*}{$\frac{C V}{283 \%}$} & \multirow{2}{*}{$\frac{\mathrm{Q} 1}{0}$} & \multirow{2}{*}{$\frac{\text { Q3 }}{0}$} & \multirow{2}{*}{$\frac{N}{8}$} & \multirow{2}{*}{$\frac{\mathrm{Cl}}{0.2}$} & \multirow{3}{*}{$\begin{array}{c}\mathrm{p} \\
.236\end{array}$} \\
\hline Month 8 & VLBW-PI & & & & & & & & & \\
\hline & $\mathrm{TI}$ & 0.4 & 0 & 0.6 & $151 \%$ & 0 & 1 & 14 & 0.3 & \\
\hline \multirow[t]{2}{*}{ Month 9} & VLBW-PI & 0.3 & 0 & 0.5 & $171 \%$ & 0 & 0.5 & 11 & 0.3 & \multirow{2}{*}{$.025^{*}$} \\
\hline & $\mathrm{TI}$ & 1.6 & 1 & 1.7 & $108 \%$ & 0 & 2 & 14 & 0.9 & \\
\hline \multirow[t]{2}{*}{ Month 10} & VLBW-PI & 0.5 & 0.5 & 0.5 & $110 \%$ & 0 & 1 & 6 & 0.4 & \multirow{2}{*}{$.071^{\star *}$} \\
\hline & $\mathrm{TI}$ & 3.5 & 3 & 3.5 & $100 \%$ & 0 & 5 & 15 & 1.8 & \\
\hline \multirow[t]{2}{*}{ Month 11} & VLBW-PI & 1.8 & 1.5 & 1.0 & $53.6 \%$ & 1 & 2.75 & 6 & 0.8 & \multirow{2}{*}{$.002^{*}$} \\
\hline & $\mathrm{TI}$ & 7.4 & 7.5 & 4.1 & $55.0 \%$ & 3 & 10 & 12 & 2.3 & \\
\hline \multirow[t]{2}{*}{ Month 12} & VLBW-PI & 3.0 & 2 & 3.5 & $118 \%$ & 1 & 3 & 5 & 3.1 & \multirow{2}{*}{$.014^{*}$} \\
\hline & $\mathrm{TI}$ & 8.9 & 9 & 3.7 & $41.8 \%$ & 7.5 & 10.5 & 11 & 2.2 & \\
\hline \multirow[t]{2}{*}{ Month 13} & VLBW-PI & 6.3 & 5 & 5.9 & $93.1 \%$ & 1.5 & 9 & 7 & 4.3 & \multirow{2}{*}{$.008^{*}$} \\
\hline & $\mathrm{TI}$ & 13.1 & 12.5 & 3.2 & $24.6 \%$ & 10 & 17 & 16 & 1.6 & \\
\hline \multirow[t]{2}{*}{ Month 14} & VLBW-PI & 6.1 & 4 & 4.5 & $73.7 \%$ & 2.5 & 9.5 & 7 & 3.4 & \multirow{2}{*}{$.002^{*}$} \\
\hline & $\mathrm{TI}$ & 15.3 & 16 & 3.4 & $22.0 \%$ & 14 & 18 & 12 & 1.9 & \\
\hline \multirow[t]{2}{*}{ Month 15} & VLBW-PI & 11.4 & 12 & 6.1 & $53.6 \%$ & 11 & 13 & 5 & 5.4 & \multirow{2}{*}{$.063^{* *}$} \\
\hline & $\mathrm{TI}$ & 17.4 & 18 & 2.7 & $15.4 \%$ & 17.3 & 18.8 & 10 & 1.7 & \\
\hline \multirow[t]{2}{*}{ Month 16} & VLBW-PI & 9.5 & 10 & 3.5 & $36.5 \%$ & 7 & 11.3 & 8 & 2.4 & \multirow{2}{*}{$.002^{*}$} \\
\hline & TI & 16.9 & 18 & 3.3 & $19.8 \%$ & 15.3 & 19 & 10 & 2.1 & \\
\hline \multirow[t]{2}{*}{ Month 17} & VLBW-PI & 11.8 & 12 & 7.1 & $60.0 \%$ & 8 & 18 & 5 & 6.2 & \multirow{2}{*}{$.080^{* *}$} \\
\hline & $\mathrm{TI}$ & 17.9 & 18.5 & 2.1 & $11.6 \%$ & 17.3 & 19 & 10 & 1.3 & \\
\hline \multirow[t]{2}{*}{ Month 18} & VLBW-PI & 13.7 & 14.5 & 4.6 & $33.4 \%$ & 9.75 & 17.5 & 10 & 2.8 & \multirow{2}{*}{$.002^{*}$} \\
\hline & $\mathrm{TI}$ & 18.6 & 19 & 2.0 & $10.7 \%$ & 18.5 & 20 & 15 & 1.0 & \\
\hline
\end{tabular}

SD: standard deviation; CV: coefficient of variance; Q1: first quartile; Q3: third quartile; Cl: confidence interval; VLBW-PI: very low birth weight preterm infants; TI: term infants. *Statistically significant. **Trend toward statistical significance.

Table 5. Correlations between expressive language and cognition.

\begin{tabular}{lcc}
\hline Months 8 to 18 & \multicolumn{2}{c}{ Expressive language vs. cognition } \\
\hline & Correlation & $\mathrm{P}$ \\
TI & $88.7 \%$ & $<.001^{\star}$ \\
VLBW-PI & $96.2 \%$ & $<.001^{\star}$ \\
\hline
\end{tabular}

VLBW-PI: very low birth weight preterm infants; TI: term infants. *Statistically significant.

8 to month 18 , since expressive language scores were unavailable prior to month 8 .

Figures 1 and 2 present the evolution of cognitive scores over the months and its relation with the development phases and the expressive language scores and its relation with the production assembly respectively for both groups.

\section{DISCUSSION}

Our results show that cognition and expressive language both emerge later in children who were VLBW preterm infants than in those who were term infants. These data corroborate those of other studies indicating that VLBW preterm infants constitute an at-risk population for subsequent disorders or delays in cognitive and language development ${ }^{1,4,5,7,9}$. Various hypotheses have been formulated to explain these deficits: preterm infants are at high risk for postnatal complications; such infants are submitted to a number of painful procedures and can be separated from their mothers for prolonged periods.

Up to month 4, the cognitive performance of the infants in the two groups was similar in terms of the early sensorimotor acquisition of the use of isolated motor schemes and following object displacement in space, corresponding to phase 1 and phase 2 of the sensorimotor period. From month 5 onward, differences between the two groups began to emerge in terms of the phases of cognitive development. While the VLBW-PI group infants were still in phase 2 of the sensorimotor period, the TI group had already entered phase 3 , which is characterized by the use of coordinated motor schemes and searching for a partly-hidden object.

In month 6, the differences between the two groups began to present statistical significance, which increased over the subsequent months.

The skills acquired during the various stages of the sensorimotor and preoperational periods are considered essential for the construction of representation and as a condition for oral language expression ${ }^{10,17,21,22}$. Authors 


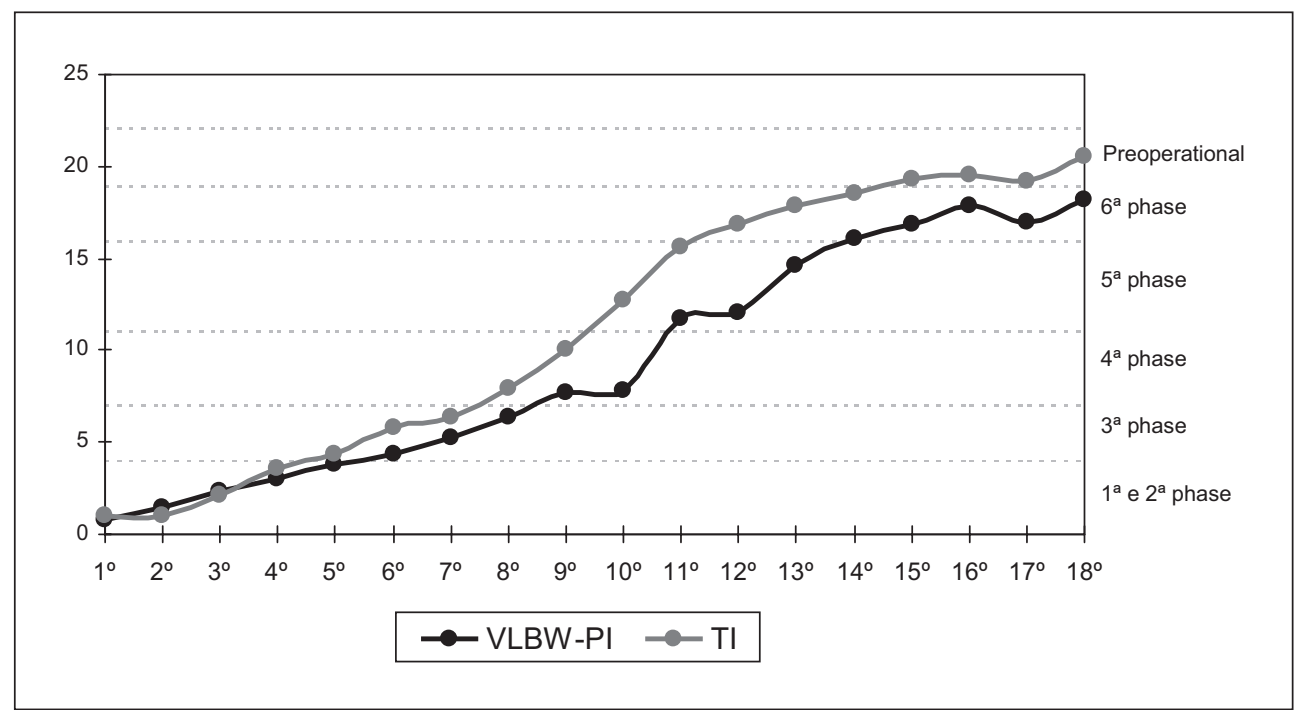

Fig 1. Evolution of cognitive scores over the months evaluated. VLBW-PI: very low birth weight preterm infants; Tl: term infants.

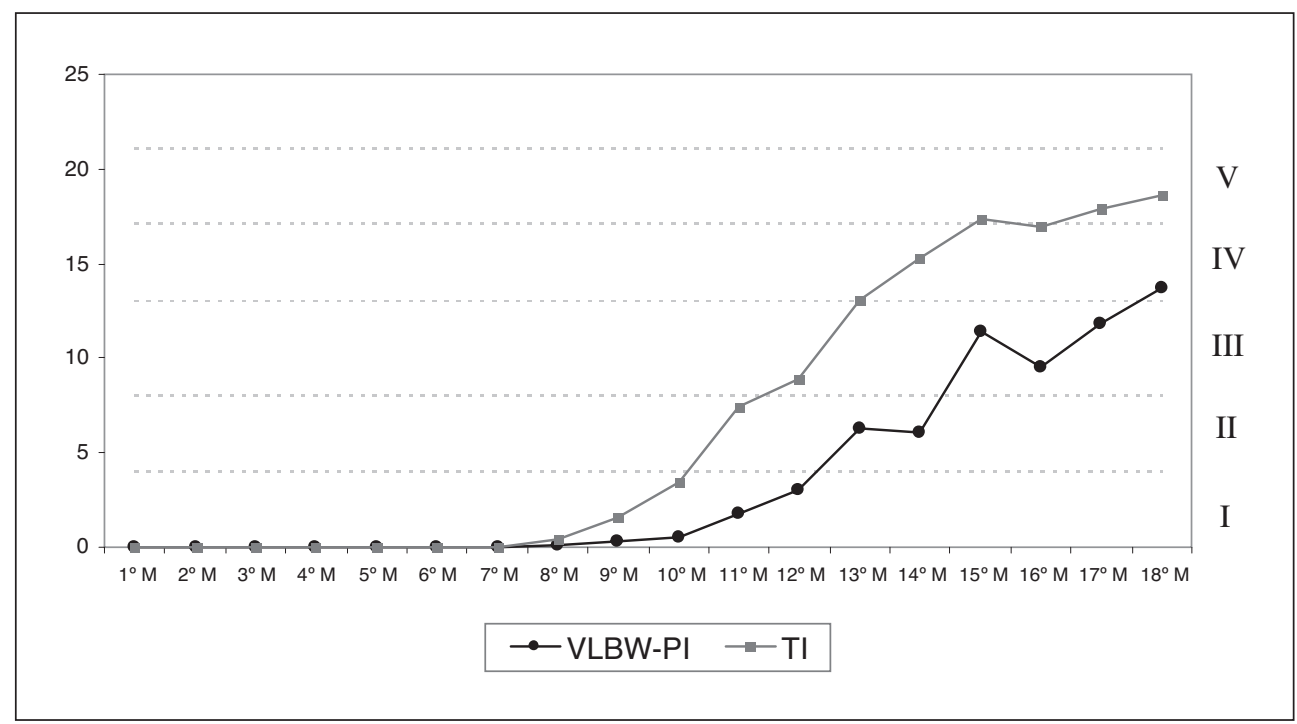

Fig 2. Evolution of expressive language scores over the months evaluated. VLBW-PI: very low birth weight preterm infants; TI: term infants.

studying language and its construction based on the principles of genetic epistemology stress the relationship between the acquisition of such skills and cognitive development, stating the importance of sensorimotor intelligence in determining the quality of linguistic development ${ }^{10,22}$.

Considering this relationship, the cognitive delay observed in the first months of life is also thought to have a qualitative and quantitative influence on the acquisition of linguistic aspects ${ }^{20,23}$.

The sequence in which children in the TI group presented acquisitions (indicators of expressive language development) was similar to that described in the literature ${ }^{12-16,22}$. Our findings corroborate those of studies showing that, in children who were preterm infants, expressive lan- guage development is delayed during the two first years of life $e^{4,24,25}$. However, the authors of those studies did not evaluate VLBW infants. In the present study, we found statistically significant differences between the two groups, expressive language development scores being higher in the TI group, in seven of the ten relevant months. The fact that, in the remaining three months evaluated, the difference presented only a tendency toward statistical significance might be attributable to the higher dropout rate in the VLBW-PI group. Other authors have reported difficulty in maintaining the number of subjects during longterm follow-up studies of preterm infants ${ }^{6}$.

The first expressive language development acquisitions were observed in both groups by month 8 . However, 
differences between the two groups became pronounced only from month 11 onward. Deferred imitation of representative gestures together with vocal production of onomatopoeias or syllables with meaning, as well as isolated production of syllables with meaning, monosyllabic words, or interjections, with or without deictic or representative gestures, corresponding to set of productions III, were observed by month 12 in the TI group, whereas they did not emerge until at least month 15 in the VLBW$\mathrm{PI}$ group. Furthermore, the production of word combinations, with or without deictic or representative gestures, corresponding to set of productions $\mathrm{V}$, was not observed in the VLBW-PI group until the study endpoint (month 18), whereas such production was observed as early as month 15 in the TI group.

Our findings for the TI group corroborate those of studies indicating that the use of deictic and representative gestures is closely related to the use of isolated words and word combinations characterizing the oral expression condition ${ }^{12,15,22}$.

An increase in the quantity and quality of representative gestures favors a quantitative and qualitative increase in oral expression, beginning with vocalizations/production of isolated syllables and evolving to the use of onomatopoeic words, isolated words, and word combinations ${ }^{12-14}$.

Our results are also in agreement with those of studies demonstrating a relationship between an increase in oral language use and a decrease in the use of gestures, attesting to the efficiency of the linguistic development ${ }^{15,16,22}$.

The significant correlation found between cognitive development and expressive language development in the present study indicates that the delay in cognitive development observed in the VLBW-PI group influenced the development of expressive language in those infants. Those in the VLBW-PI group entered stage 6 of the sensorimotor period, characterized by the presence of deferred imitation, which allows the emergence of the first words, only in month 14, and only in month 15 did those infants begin to produce vocal onomatopoeia, meaningful syllables, or interjections, as has been previously reported ${ }^{13,14}$. In the present study, VLBW infants with a corrected age of 18 months did not reach the preoperational period, nor were they capable of producing combinations of two or more words. The relationships found in the present study among the emergence of representative gestures, symbolic play development, the acquisition of the first words, and the first use of word combinations corroborate the findings of other authors ${ }^{14,15,22,26}$.

Another factor that should be considered is the great variability in and heterogeneity among small children with normal language development, which makes it difficult to predict, which any degree of reliability, later language skills from the initial language development ${ }^{27}$. In order to reduce this bias, we included the TI group as a suitable example of how the development of preterm children can be compared to that of healthy term children.

Some studies comparing preterm and term children report that the initial differences, especially certain aspects, can disappear in the first years of life, lending credence to the concept of plasticity and recovery of cognition and receptive vocabulary over time in children who were VLBW infants but had no neurologic disorders'. Various authors indicate the importance of long-term followup evaluation, for at least 18 months, in order to identify severe developmental problems ${ }^{28}$.

The findings of the present study should serve to stimulate considerable reflection regarding cognitive and the expressive language development in VLBW preterm infants: there is a need for systematic follow-up evaluation protocols that provide qualitative and quantitative information in order to define the true needs of such infants and identify the ideal moment for speech-language intervention, as has been suggested by various authors ${ }^{2,20,29,30}$.

Our results lead us to conclude that the PELCDO Protocol for Expressive Language and Cognition Development Observation used in the present study allows the description, the performance analyses of the children and the placement and follow-up evaluation of the child in terms of knowledge and expressive language development during the sensorimotor period and the beginning of preoperational period in a objective form. The statistic differences found between the two groups evaluated reveal not only a delay in the development of cognition and expressive language among VLBW preterm infants but also the relationship existing between the two skills.

\section{REFERENCES}

1. Ment LR, Vohr B, Allan W, et al. Change in cognitive function over time in very low-birth-weight infants. JAMA 2003;289:705-711.

2. Souza R, Andrade CRF. O perfil da fluência de fala e linguagem de crianças nascidas pré-termo. Pediatria (São Paulo) 2004;26:90-96.

3. Taylor HG, Minich NM, Klein N, et al. Longitudinal outcomes of very low birth weight: neuropsychological findings. J Int Neuropsychol Soc 2004;10:149-163.

4. Cusson RM. Factors influencing language development in preterm infants. J Obstet Gynecol Neonatal Nurs 2003;32:402-409.

5. Jansson-Verkasalo E, Korpilahti P, Jäntti V, et al. Neuropsychologic correlates of deficient phonological representations and object naming in prematurely born children. Clin Neurophysiol 2004;115:179-187.

6. Aylward GP. Neurodevelopmental outcome of infants born prematurely. J Dev Behav Pediatr 2005;26:427-440.

7. Caravale B, Tozzi C, Albino G, Vicari S. Cognitive development in low risk preterm infants at 3-4 years of life. Arch Dis Child Fetal Neonatal 2005;90:474-479. 
8. Hintz SR, Kendrick DE, Vohr B, Poole K, Higgins RD. Changes in neurodevelopmental outcomes at 18 to 22 months' corrected age among infants of less than 25 weeks' gestational age born in 1993-1999. Pediatrics 2005;115:1645-1651.

9. Sansavini A, Guarini A, Alessandroni R, et al. Early relations between lexical and grammatical development in very immature Italian preterms. J Child Lang 2006;33:199-216.

10. Sinclair H, Bertoud I, Gerard J, Veneziano E. Construtivisme et psycholinguistique génétique. Arch Psychol 1985;53:37-60.

11. Bates E, Dick F. Language, gesture and the developing brain. Dev Psychobiol 2002;40:293-310.

12. Capone NC, McGregor KK. Gesture development: a review for clinical and research practices. J Speech Lang Hear Res 2004;47:173-186.

13. Iverson JM, Golding-Meadow S. Gestures paves the way for language development. Psychol Sci 2005;16:367-371.

14. Ozçaliskan S, Goldin-Meadow S. Gesture is at the cutting edge of early language development. Cognition 2005;96:101-113.

15. Iverson JM, Longobardi E, Caselli MC. Relationship between gestures and words in children with Down's syndrome and typically developing children in the early stages of communicative development. Int J Lang Commun Disord 2003;38: 179-197.

16. McEachern D, Haynes WO. Gesture-speech combinations as transition to multiword utterances. Am J Speech Lang Pathol 2004;13:227-235.

17. Andrade RV, Limongi SC. A emergência da expressão comunicativa na criança com síndrome de Down. Pró-Fono 2007;19:387-392.

18. Adrien JL, Rossignol-Deletang N, Martineau J, Couturier G, Barthelemy C. Regulation of cognitive activity and early communication development in young autistic, mentally retarded, and young normal children. Dev Psychobiol 2001;39:124-136.

19. Bühler KEB, Flabiano FC, Limongi SCO, Befi-Lopes DM. Protocolo para observação do desenvolvimento cognitivo e de linguagem expressiva (PODCLE). Rev Soc Bras Fonoaudiol 2008;13:60-68.
20. Buhler KECB. Desenvolvimento cognitivo e de linguagem expressiva em bebês pré-termo muito baixo peso em seus estágios iniciais. Tese, Faculdade de Medicina, Universidade de São Paulo. São Paulo, 2008.

21. Limongi SCO. A construção da linguagem na criança paralítica cerebral. In: Limongi SCO (Ed). Paralisia cerebral: processo terapêutico em linguagem e cognição. Carapicuíba: PróFono;2000.

22. Camaioni L, Aureli T. Trajectoires développementales et individuelles de la transition vers la communication symbolique. Enfance 2002;3:259-275.

23. Tommiska V. Heinonen $\mathrm{K}$, Kero $\mathrm{P}$, et al. A national two year follow up study of extremely low birthweight infants born in 1996-1997. Arch Dis Child Fetal Neonatal 2003;88:29-35.

24. Pereira MR, Funayama CAR. Avaliação de alguns aspectos da aquisição e desenvolvimento da linguagem de crianças nascidas pré-termo. Arq Neuropsiquiatr 2004;62:641-648.

25. Oliveira LN, Lima MCMP, Gonçalves VMG. Acompanhamento de lactentes com baixo peso ao nascimento: aquisição de linguagem. Arq Neuropsiquiatr 2003;61:802-807.

26. Takiuchi N. Relações entre maturidade simbólica e desenvolvimento lingüístico em crianças com distúrbios específicos de desenvolvimento de linguagem. Tese, Faculdade de Filosofia, Letras e Ciências Humanas, Universidade de São Paulo. São Paulo, 2006.

27. Bruce B, Kornfält R, Radeborg K, et al. Identifying children at risk for language impairment: screening of communication at 18 months. Acta Paediatr 2003;92: 1090-1095.

28. Hack M, Klein NK, Taylor HG. Long-term developmental outcomes of low birth weight infants. Future Child 1995;5:176-196.

29. Isotani SM, Pedromônico MRM, Perissinoto J, et al. O desenvolvimento de crianças nascidas pré-termo no terceiro ano de vida. Folha Med 2002;121:85-92.

30. Gianni ML, Picciolini O, Ravasi M, et al. The effects of an early developmental mother-child intervention program on neurodevelopment outcome in very low birth weight infants: a pilot study. Early Hum Dev 2006;82:691-695. 